\title{
Social Distancing, Lockdown Obligatory, and Response Satisfaction During COVID-19 Pandemic: Perception of Nigerian Social Media Users
}

\author{
Olalekan Seun Olagunju ${ }^{1}$, Obasanjo Afolabi Bolarinwa ${ }^{2 *}$, Tesleem Babalola ${ }^{2}$ \\ ${ }^{1}$ Department of Demography \& Social Statistics, Obafemi Awolowo University, Nigeria. \\ ${ }^{2}$ Department of Public Health, School of Nursing and Public Health Medicine, \\ University of KwaZulu-Natal, South Africa.
}

*Corresponding author email: bolarinwaobasanjo@gmail.com

Received: 24 May 2020 / Accepted: 02 June 2020 / Published: 08 June 2020

\begin{abstract}
Background: Pandemics are challenging for clinical and public health agencies and policymakers because of the scientific and medical uncertainty that accompanies novel viruses like COVID-19 makes an increase of morbidity and mortality prominent. Consequently, there is a need to evaluate the public perception of social distancing, lockdown obligatory, and response satisfactory during the pandemic. Methods: This cross-sectional survey used an anonymous online google based questionnaire to collect data from respondents via social media platforms. The online survey was conducted among social media users from 1st to 30th April 2020. A snowball sampling technique was employed to recruit respondents for the survey. A total of 1,131 respondents responded across the country.

Results: Nine out of every ten respondents believed that social distancing is an effective measure to reduce the spread of COVID-19. Also, 8 out of every ten respondents agreed with the lockdown measures. However, just 36.8\% think their government is doing enough to stop the outbreak, and only $25 \%$ of the respondents were satisfied with the country's response to the worldwide epidemic. The age of respondents was found to be significantly associated with satisfaction with emergency response during pandemics.

Conclusion: It could be concluded that Nigerian public accepted social distancing as an effective way of curbing the spread of COVID-19 and general acceptance on lockdown obligatory; however, more than half of respondents expressed non-satisfactory with government and other agencies responses during the pandemics.
\end{abstract}

Keywords: COVID-19, Nigeria, Perception, Lockdown, Social distancing

\section{Introduction}

On 30th January 2020, the World Health Organization (WHO) declared that the novel coronavirus (2019-nCoV) epidemic as a public health emergency of international concern(Makoni, 2020). The Coronavirus Disease of 2019, also known as COVID-19, is a rapidly spreading disease caused by the Severe Acute Respiratory Syndrome Coronavirus 2 (SARS-CoV2)(La et al., 2020). The virus has extraordinary spreading properties and is causing high rates of both morbidity and mortality(Pakpour \& Griffiths, 2020) and has affected countries in all inhabited continents(Jittrapirom \& Tanaksaranond, 2020; Lopez, Vasu, \& Gallemore, 2020).

Pandemics are challenging for clinical and public health agencies and policymakers because of the scientific and medical uncertainty that accompanies novel viruses like COVID-19(Williams, Armitage, Tampe, \& Dienes, 2020) makes an increase of morbidity and mortality prominent. As at the time of writing this manuscript, over 3.5 Million cases have been reported globally (University, 2020). The virus, however, spreads faster than its two ancestors; SARS-CoV and (MERS-CoV) but has a lower fatality of 2-3\%(Nazli, 
Social Distancing, Lockdown Obligatory, and Response Satisfaction During COVID-19 Pandemic:

Raheem, \& Kishore, 2020). Older men with medical comorbidities are more likely to get infected with worse outcomes. Severe cases can lead to cardiac injury, respiratory failure, acute respiratory distress syndrome, and death(Wang et al., 2020).

The ongoing coronavirus disease is now spreading fast in Africa, with most cases so far reported being importations from other countries and few community transmissions in those who do not have recent travel history. We all know how fragile health systems are on the African continent; they are already overwhelmed by many outbreaks(Engel; Makoni, 2020); thus, this might affect efficiency and response.

The first case of COVID-19 in Nigeria was detected on 27th February 2020, after which a series of immediate interventions were put in place by the Government of Nigeria in response to the virus(Adegboye, Adekunle, \& Gayawan, 2020).

The Governments at the Federal and States level later announced the restriction of public gathering. Markets were closed excepted for essential food items, and medicine stores can open(Shehu \& Rao, 2020) when the numbers keep growing. A total of 81 COVID-19 pandemic cases was confirmed as of 27th March, 2020(AbdulAzeez), and as jumped to over 2,500 reported cases in 35 states, including FCT, Abuja as at 4th May, 2020(NCDC, 2020) and the cases are growing which might overwhelm the healthcare system(Paterlini, 2020).

The high transmission rate of this virus, as well as the lack of vaccines and specific pharmaceutical treatments for COVID-19, has posed severe challenges in controlling the spread of the disease. To curb this spreading, it is necessary to implement non-medical measures such as the promotion of personal protection practices, which include the use of face masks, following personal hygiene, and social distance from possibly infected cases(Khosravi, 2020; Meier et al., 2020; Van Bavel et al., 2020; Vijayaraghavan \& SINGHAL, 2020). The COVID-19 pandemic requires an effort to coordinate the actions of government and society unmatched in recent history(Merkley et al., 2020), and the ability of the government to reduce transmission rate is dependent on compliance with public health advice on social distancing(Andersen, 2020; Atchison et al., 2020; Khosravi, 2020; Lunn et al., 2020).

Social and physical distancing generally defined as deliberately keeping a distance of at least 2 meters (6 feet) from other people(Abu-Akel, Spitz, \& West, 2020). Social distancing has been an essential tool in reducing infections and mortality during previous pandemics(Andersen, 2020), and the effective and timely management of diseases is much dependent on social distancing behavior(Geldsetzer, 2020; Qazi et al., 2020).

Preliminary findings from Italy and the United States suggest that, while public messaging is generally being adhered to, this is true to a lesser degree among young adults(Abu-Akel et al., 2020). Also, a global survey conducted in 58 countries had a negative perception of COVID-19 response from government (Fetzer et al., 2020). The fight against highly contagious COVID-19 demands and recommends the spirit of cooperation from every individual of the society and solidarity among the citizens across the socioeconomic classes(Ganguly, Misra, \& Goli, 2020). Consequently, there is a need to evaluate Nigerian social media user perception on social distancing, lock obligatory, and response satisfactory on the outbreak of COVID-19 pandemic in Nigeria.

\section{Materials and Methods}

\subsection{Setting and Participants}

This cross-sectional survey used an anonymous online google based questionnaire to collect data from respondents via social media platforms, such as Facebook, WhatsApp, and Twitter. The google form link was shared on this platform for Nigerians to participate. A snowball sampling technique was employed to recruit more Nigerians who are active on social media platforms living in the country's six geopolitical zones during the COVID-19 pandemic by encouraging those sent the link to share with their contacts kindly. The online survey ran from 1st April to 30th April 2020 for one month in Nigeria and a total of 1,131 respondents across the country. 


\subsection{Procedure}

Due to the Nigerian government's social distance rules and curfew/lockdown enforcement, physical interaction was not possible, so online promotion of the survey was done, and existing study participants were urged to send the web link of the survey to potential respondents. They completed the questionnaires hosted on Google online survey platform. Participation was completely consensual, anonymous, and voluntary. Informed consent was obtained from all respondents by asking if they were willing to proceed with the filling of the online questionnaire for this study, and those who agreed were taking to the next step, which involved the filling of the questionnaire, those that picked otherwise were signed-out of the online questionnaire immediately.

\subsection{Instruments}

Socio-demographic data were elicited from the respondents on variables such as gender, age, educational qualification, professional background while, and outcome variables question asked were the Perception of Nigerian social media users during COVID-19 pandemic on social distancing, lockdown obligatory and response satisfaction by the government.

\subsection{Operationalization of variables}

This section describes the variables used in this study. The variables age of respondent, gender, level education, and background were used as explanatory variables. The outcome variables in this study are social distancing/self-isolation, lockdown obligatory, and respondents' satisfaction with the country's response to the COVID-19 pandemic.

Social distancing/self-isolation refers to whether respondents think social distance/self-isolation is an effective way to reduce the COVID-19 virus spread. Those that think social distancing/self-isolation is an effective measure to reduce the spread were coded "Yes" and "No" were given to those that reported otherwise.

Lockdown obligatory refers to whether respondents agree with lockdown obligatory. Those that agree with the lockdown measure were coded "Yes" and "No" were given to those that reported otherwise.

Satisfaction with the country's response to COVID-19 refers to respondents' level of satisfaction with the country's response to the COVID-19 pandemic. Respondents could express the level of satisfaction. The responses ranging from 1 (not satisfied) to 5 (very satisfied). The median score was used to categorized respondents into satisfied and not satisfied. The median score was 3 , respondents that fall between 1 and 3 were coded not satisfied, and respondent that score 4 and 5 were coded satisfied.

\subsection{Statistical Analysis}

The data were analyzed using Stata 14 software. The results were presented in the form of tables and text using frequencies and percentages to describe the study population concerning relevant variables. Further, to identify socio-demographic factors associated with the outcome variables, chi-square analysis was performed. Variables with p-value $<0.05$ in the bivariate analysis were significant predictors.

\section{Results}

\subsection{Socio-demographic of respondents}

Table 1 represents respondent socio-demographic. The table shows that over $77 \%$ of the respondents were between 18 to 39 years, while the remaining were between 40 years and above. Gender shows that $41.9 \%$ were male, $57.7 \%$ were female, and $0.4 \%$ prefer not to say their gender. The table shows that respondents were well educated in that 5 out of every $10(52.0 \%)$ had a bachelor's degree, about 4 out of every ten had post-graduate, and only $0.3 \%$ had no formal education. 
Social Distancing, Lockdown Obligatory, and Response Satisfaction During COVID-19 Pandemic:

Table 1: Socio-demographic of respondents

\begin{tabular}{lcc}
\hline Variable & $\mathbf{n}=\mathbf{1 1 3 1}$ & $\mathbf{\%}$ \\
\hline Age group & 495 & 43.8 \\
$18-29$ & 383 & 33.8 \\
$30-39$ & 172 & 15.2 \\
$40-49$ & 63 & 5.6 \\
$50-59$ & 16 & 1.4 \\
$60-69$ & 2 & 0.2 \\
$>70$ & & \\
Gender & 474 & 42.1 \\
Male & 652 & 57.9 \\
Female & & \\
Level of education & 3 & 0.3 \\
No formal education & 61 & 5.4 \\
High school & 589 & 52.0 \\
College (Bachelor) & 478 & 42.3 \\
Post-graduate & & \\
Background & 438 & 38.7 \\
Non-scientific/non-medical & 693 & 61.3 \\
Scientific/medical & & \\
\hline
\end{tabular}

\subsection{Social distancing and response satisfactory}

Table 2 represents views concerning social distancing. 9 out of 10 respondents believed that social distancing is an effective measure to reduce the spread of COVID-19. A further question was asked about ideal distance for an effective social distancing, 65\% reported 1-2 meters, $23.7 \%$ reported 3-5 meters, 8.3\% reported more than 5 meters, and $1.2 \%$ reported less than 1 meter.

Concerning response satisfactory, $36.8 \%$ think their government is doing enough to stop the outbreak. Almost half (48.4\%) believe the World Health Organization (WHO) is doing enough to stop the global pandemic. Only $25 \%$ of respondents were satisfied with their county's response to the worldwide epidemic. Almost half (47.0\%) of the respondents were very satisfied with the updates from social media concerning COVID-19 pandemic coverage.

Table 2: Social distancing and Response satisfaction

\begin{tabular}{lcc}
\hline Variable - Social distancing & $\mathbf{N}=\mathbf{1 1 3 1}$ & $\mathbf{\%}$ \\
\hline Social distancing/self-isolation is an effective measure to reduce COVID-19 & spread \\
& & \\
No & 49 & 4.3 \\
Yes & 1082 & 95.7 \\
Ideal distance between two people during social distancing & \\
Less than 1 meter & 14 & 1.2 \\
1-2 meters & 735 & 65.0 \\
3-5 meters & 268 & 23.7 \\
$>5$ meters & 94 & 8.3 \\
Don't know & 20 & 1.8 \\
\hline
\end{tabular}


Olalekan Seun Olagunju et al., Adv. J Social Sci.; Vol. 7, Issue 1, pp: 44-53, 2020

\begin{tabular}{lcc}
\hline Variable - Response satisfactory & $\mathbf{N}=1131$ & $\mathbf{\%}$ \\
\hline Do you think government is doing enough to stop the global outbreak & 42.1 \\
No & 476 & 36.8 \\
Yes & 416 & 21.1 \\
Maybe & 239 & \\
Do you think WHO is doing enough to stop the global pandemic & 23.8 \\
No & 270 & 48.4 \\
Yes & 547 & 27.8 \\
Maybe & 314 & \\
How satisfied are you to your county's response & & 75.0 \\
Not satisfied & 848 & 25.0 \\
Satisfied & 283 & 47.0 \\
How satisfied are you with the social media coverage of COVID-19 pandemic \\
Very satisfied/keeps me updated & 532 & 14.8 \\
Makes me worry more/stressful & 167 & 10.4 \\
Not enough information & 118 & 19.4 \\
There are more lies than truth & 219 & 1.5 \\
I don't follow any social media update & 17 & 6.9 \\
No comment & 78 & \\
\hline
\end{tabular}

Fig 1 represents respondents' responses concerning lockdown obligatory by their country. 8 out of every ten respondents agree with the lockdown measures.

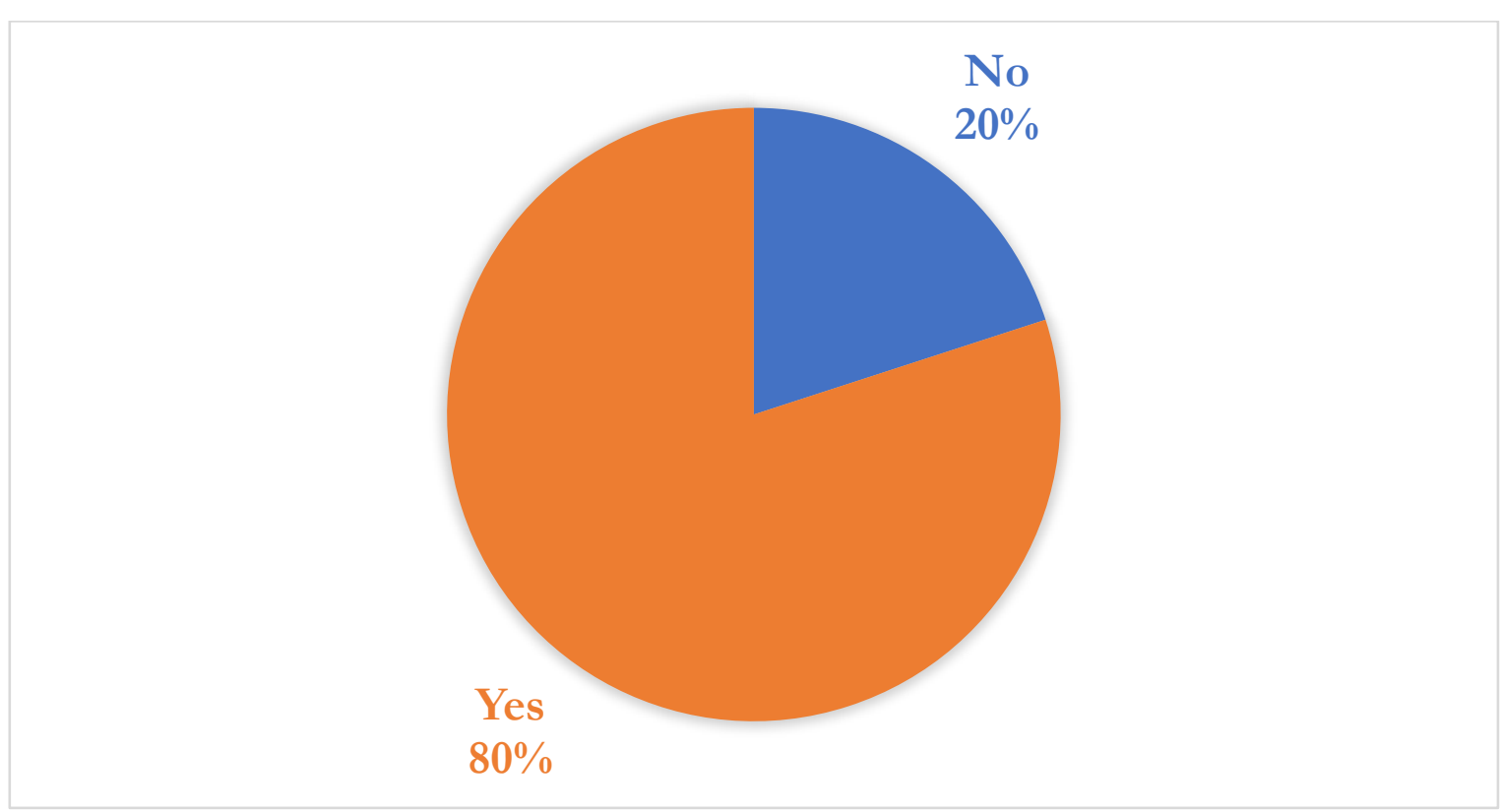

Fig 1: Do you agree with the obligatory lockdown measures in your country

\subsection{Association between socio-demographic of the respondent and social distancing/self- isolation}

Table 3 presents the association between respondent's socio-demographic and what they think about social distancing/self-isolation. The table shows that as respondent age increases, the proportion that think social distancing/self-isolation is an effective way of reducing the spread of the virus decreases. More female thinks that social distancing/self-isolation is effective. Most respondents with at least high school think 
Social Distancing, Lockdown Obligatory, and Response Satisfaction During COVID-19 Pandemic:

social distancing/self-isolation is most effective. Concerning the respondent's background, more than half of the respondents that think social distancing/self-isolation is an effective way were from science/medical background. None of the respondent socio-demographic was statistically significant in this study.

Table 3: Association between socio-demographic of the respondent and social distancing/self-isolation

\begin{tabular}{lcccc}
\hline Variable & No & Yes & Total & $\mathbf{X}^{2}$, p-value \\
\hline Age group & $\mathbf{N}=\mathbf{4 9}$ & $\mathbf{N}=\mathbf{1 0 8 2}$ & $\mathbf{N}=1131$ & \\
$18-29$ & $24(49.0)$ & $471(43.5)$ & $495(43.8)$ & \\
$30-39$ & $16(32.6)$ & $367(33.9)$ & $383(33.9)$ & $4.71,0.453$ \\
$40-49$ & $4(8.2)$ & $168(15.5)$ & $172(15.2)$ & \\
$50-59$ & $3(6.1)$ & $60(5.6)$ & $63(5.6)$ & \\
$60-69$ & $2(4.1)$ & $14(1.3)$ & $16(1.4)$ & \\
$>70$ & $0(0.0)$ & $2(0.2)$ & $2(0.2)$ & \\
\hline Gender & & & & $1.87,0.171$ \\
Male & $16(32.7)$ & $458(42.5)$ & $474(42.1)$ & \\
Female & $33(67.3)$ & $619(57.5)$ & $652(57.9)$ & \\
\hline Level of education & & & & \\
No formal education & $0(0.0)$ & $3(0.3)$ & $3(0.3)$ & \\
High school & $5(10.2)$ & $56(5.2)$ & $61(5.4)$ & \\
College (Bachelor) & $31(63.3)$ & $558(51.5)$ & $589(52.0)$ & \\
Post-graduate & $13(26.5)$ & $465(43.0)$ & $478(42.3)$ & \\
\hline Background & $16(32.7)$ & $422(39.0)$ & $438(38.7)$ & \\
Non-scientific/non-medical & $33(67.3)$ & $660(61.0)$ & $693(61.3)$ & \\
Scientific/medical & & & & \\
\hline \hline & & & & \\
& & & & \\
\hline
\end{tabular}

\subsection{Association between socio-demographic of respondent and lockdown obligatory}

Table 4 presents the association between respondent's socio-demographic and opinion of the respondents with lockdown obligatory/measurement to curb the spread of the COVID-19 virus. The proportion of respondents that agree with lockdown obligatory/measurement decreases as the age group of respondents increases. More female respondents agree with country lockdown obligatory/measurement. Most respondents with at least high school agree with lockdown obligatory/measurement reduce virus spread. Concerning respondent's background, about $63 \%$ of the respondents that coincide with the country's lockdown obligatory/measurement were from science/medical background, and this is the only respondent's socio-demographic variable that was statistically significant in this study $(\mathrm{p}<0.05)$. 
Olalekan Seun Olagunju et al., Adv. J Social Sci.; Vol. 7, Issue 1, pp: 44-53, 2020

Table 4: Association between socio-demographic of respondent and lockdown obligatory

\begin{tabular}{|c|c|c|c|c|}
\hline Variable & No & Yes & Total & $\mathrm{X}^{2}, \mathrm{p}$-value \\
\hline Age group & $\mathrm{N}=226$ & $\mathrm{~N}=905$ & $\mathrm{~N}=1131$ & \multirow{7}{*}{$6.88,0.230$} \\
\hline $18-29$ & $108(47.8)$ & $387(42.8)$ & $495(43.8)$ & \\
\hline $30-39$ & $78(34.5)$ & 305 (33.7) & $383(33.9)$ & \\
\hline $40-49$ & $30(13.3)$ & $142(15.7)$ & $172(15.2)$ & \\
\hline $50-59$ & $8(3.6)$ & $55(6.1)$ & $63(5.5)$ & \\
\hline 60-69 & $1(0.4)$ & $15(1.6)$ & $16(1.4)$ & \\
\hline$>70$ & $1(0.4)$ & $1(0.1)$ & $2(0.2)$ & \\
\hline \multicolumn{5}{|l|}{ Gender } \\
\hline Male & $102(45.3)$ & $372(41.3)$ & $474(42.1)$ & \multirow[t]{2}{*}{$1.21,0.272$} \\
\hline Female & $123(54.7)$ & $529(58.7)$ & $652(57.9)$ & \\
\hline \multicolumn{5}{|l|}{ Level of education } \\
\hline No formal education & $0(0.0)$ & $3(0.3)$ & $3(0.3)$ & \multirow{4}{*}{$3.89,0.274$} \\
\hline High school & $9(4.0)$ & $52(5.8)$ & $61(5.4)$ & \\
\hline College (Bachelor) & $129(57.1)$ & $460(50.8)$ & $589(52.1)$ & \\
\hline Post-graduate & $88(38.9)$ & $390(43.1)$ & $478(42.2)$ & \\
\hline \multicolumn{5}{|l|}{ Background } \\
\hline Non-scientific/non-medical & $105(46.5)$ & $333(36.8)$ & $438(38.7)$ & \multirow[t]{2}{*}{$7.12,0.008^{* *}$} \\
\hline Scientific/medical & $121(53.5)$ & $572(63.2)$ & $693(61.3$ & \\
\hline
\end{tabular}

\subsection{Association between socio-demographic of respondent and satisfaction with the country's response}

Table 5 presents respondents' socio-demographic and satisfaction with the country's response to COVID19 pandemic. The table shows that the age group of respondents was statistically significant $(p<0.05)$ with respondent's satisfaction with the country's response to the pandemic, like the age group of respondents increases the proportion of respondents who were not satisfied with the county's response to the situation decreases. More than half of the respondents that were not satisfied with the country's response were female; almost all the respondents with at least a high school level of education were not satisfied with the country's response to the COVID-19 pandemic. Concerning the respondent's background, $61.3 \%$ of the respondents that were not satisfied with the country's response to the COVID-19 pandemic were from scientific/medical background.

Table 5: Association between socio-demographic of respondent and satisfaction with the country's response

\begin{tabular}{lcccc}
\hline \hline Variable & Not satisfied & Satisfied & Total & $\mathbf{X}^{2}$, p-value \\
\hline Age group & $\mathbf{N}=\mathbf{8 4 8}$ & $\mathbf{N}=\mathbf{2 8 3}$ & $\mathbf{N}=\mathbf{1 1 3 1}$ & \\
$18-29$ & $379(44.7)$ & $116(41.0)$ & $495(43.8)$ & \\
$30-39$ & $300(35.4)$ & $83(29.3)$ & $383(33.9)$ & $17.17,0.004^{* *}$ \\
$40-49$ & $120(14.2)$ & $52(18.4)$ & $172(15.2$ & \\
$50-59$ & $39(4.6)$ & $24(8.5)$ & $63(5.5)$ & \\
$60-69$ & $8(0.9)$ & $8(2.8)$ & $16(1.4)$ & \\
$>70$ & $2(0.2)$ & $0(0.0)$ & $2(0.2)$ &
\end{tabular}


Social Distancing, Lockdown Obligatory, and Response Satisfaction During COVID-19 Pandemic: .............

\begin{tabular}{lcccc}
\hline Gender & $354(41.8)$ & $120(42.9)$ & $474(42.1)$ & $0.09,0.766$ \\
Male & $492(58.2)$ & $160(57.1)$ & $652(57.9)$ & \\
Female & $2(0.2)$ & $1(0.4)$ & $3(0.3)$ & \\
\hline Level of education & $47(5.6)$ & $14(5.0)$ & $61(5.4)$ & $0.33,0.954$ \\
No formal education & $443(52.2)$ & $146(51.5)$ & $589(52.1)$ & \\
High school & $356(42.0)$ & $122(43.1$ & $478(42.2)$ & \\
College (Bachelor) & & $110(38.9)$ & $438(38.7)$ & $0.00,0.955$ \\
Post-graduate & $328(38.7)$ & $173(61.1)$ & $693(61.3)$ & \\
\hline Background & $520(61.3)$ & & \\
Non-scientific/non-medical & & & \\
Scientific/medical &
\end{tabular}

\section{Discussion}

The purpose of this study is to evaluate Nigerian social media user's perception of social distancing, lock obligatory, and response satisfactory concerning COVID-19 pandemic in Nigeria. According to WHO, the COVID-19 virus spreads primarily from person to person through small droplets from the nose or mouth, which are expelled when a person with COVID-19 coughs, sneezes or speaks. People can catch COVID19 if they breathe in these droplets from a person infected with the virus. Therefore, the government/ministry of health recommends social distancing/self-isolation. Self-isolation is a measure taken by those who have COVID-19 symptoms to avoid infecting others in the community, including family members, while social distancing means being physically apart. Finding from the study shows that almost all the respondents think social distancing/self-isolation is an effective way to reduce the spread. In addition to social distancing, WHO recommends keeping at least 1-meter distance from others. This is a general measure that everyone should take, even if they are well with no known exposure to COVID-19. Finding from this study shows that almost all the respondents know the ideal distance.

Lockdown is a situation whereby people are not allowed to enter or leave a building or area freely because of an emergency. This is the measure put in place globally, given the rapid spread of the virus, social lockdown is urgent to bring overall transmission down, and see whether testing followed by isolation could be enough. This is all to flatten the curve or reduce infections and spread cases out over a longer time frame to avoid overwhelming health systems. Finding from the study shows that most of the respondents agreed with the government concerning lockdown obligatory.

Lockdown may continue since there is no approved drug/vaccine for COVID-19. Life under lockdown brings many challenges, and there have been many instances of people flouting advice on social distancing or isolation. Country response to the situation with regards to palliative supports and timely and accurate information about the virus is critical at this period. Finding from this study shows that about $75 \%$ of respondent were not satisfied with the Nigerian government response to COVID-19 pandemic, and this is significantly associated with the age group. This may be that the young/active population in Nigeria believed that the government could do better concerning the number of people tested per day; the government can subscribe to other means to distributes palliative and more proactive in disseminating information.

\section{Conclusion}

This study concludes that Nigeria social media users understood the measure of social distance about COVID-19 pandemic as most respondents tend towards the idea measures. Lockdown obligatory also has support of social media users as most applauded the government decision on lockdown obligatory. 
Olalekan Seun Olagunju et al., Adv. J Social Sci.; Vol. 7, Issue 1, pp: 44-53, 2020

However, Nigeria social media users believed that Nigeria government is not doing enough in-term of response to the pandemic. Also, none of the social demographic variables have significant association with ideal knowledge of social distance measurement, while only background of the respondents is the only socio-demographic variables that is significantly associated with perception of lockdown. Only age of social media users is significantly associated with country's response. In the same vein, there is positive perception about social distancing, lockdown obligatory and county's response among Nigeria social media users.

\section{Declarations}

\subsection{Study Limitations}

The study was conducted among social media users in Nigeria and can't be used to generalize for the country.

\subsection{Informed Consent}

Consent was sought from the participants before filling the questionnaire. Those that declined were not allowed to participate. Access was only given to those who agreed to participant in the survey.

\subsection{Competing Interests}

The authors declared that no conflict of interest exist in this publication.

\section{How to Cite this Article:}

Olagunju, O., Bolarinwa, O., \& Babalola, T. (2020). Social Distancing, Lockdown Obligatory, and Response Satisfaction During COVID-19 Pandemic: Perception of Nigerian Social Media Users. Advanced Journal of Social Science, 7(1), 44-53. https://doi.org/10.21467/ajss.7.1.44-53

\section{References}

AbdulAzeez, A. A. MORE PREPAREDNESS ON CORONAVIRUS DISEASE-2019 (COVID-19) IN NIGERIA.

Abu-Akel, A., Spitz, A., \& West, R. (2020). Who is listening? Spokesperson Effect on Communicating Social and Physical Distancing Measures During the COVID-19 Pandemic.

Adegboye, O., Adekunle, A. I., \& Gayawan, E. (2020). Novel Coronavirus in Nigeria: Epidemiological analysis of the first 45 days of the pandemic. medRxiv.

Andersen, M. (2020). Early evidence on social distancing in response to COVID-19 in the United States. Available at SSRN 3569368.

Atchison, C. J., Bowman, L., Vrinten, C., Redd, R., Pristera, P., Eaton, J. W., \& Ward, H. (2020). Perceptions and behavioural responses of the general public during the COVID-19 pandemic: A cross-sectional survey of UK Adults. medRxiv.

Engel, U. Public health policies beyond the state: A socio-spatial analysis of early responses to Covid-19 in Africa, 2020.

Fetzer, T., Witte, M., Hensel, L., Jachimowicz, J., Haushofer, J., Ivchenko, A., . . Fiorin, S. (2020). Global Behaviors and Perceptions in the COVID-19 Pandemic.

Ganguly, D., Misra, S., \& Goli, S. (2020). India's COVID-19 Episode: Resilience, Response, Impact and Lessons.

Geldsetzer, P. (2020). Knowledge and Perceptions of COVID-19 Among the General Public in the United States and the United Kingdom: A Cross-sectional Online Survey. Annals of internal medicine.

Jittrapirom, P., \& Tanaksaranond, G. (2020). An exploratory survey on the perceived risk of COVID-19 and travelling.

Khosravi, M. (2020). Perceived Risk of COVID-19 Pandemic: The Role of Public Worry and Trust. Electron J Gen Med. 2020; 17 (4): em203. In.

La, V.-P., Pham, T.-H., Ho, M.-T., Nguyen, M.-H., P Nguyen, K.-L., Vuong, T.-T., . . Vuong, Q.-H. (2020). Policy Response, Social Media and Science Journalism for the Sustainability of the Public Health System Amid the COVID-19 Outbreak: The Vietnam Lessons. Sustainability, 12(7), 2931.

Lopez, C. E., Vasu, M., \& Gallemore, C. (2020). Understanding the perception of COVID-19 policies by mining a multilanguage Twitter dataset. arXiv preprint arXiv:2003.10359.

Lunn, P. D., Timmons, S., Barjaková, M., Belton, C. A., Julienne, H., \& Lavin, C. (2020). Motivating social distancing during the Covid-19 pandemic: An online experiment.

Makoni, M. (2020). Africa prepares for coronavirus. The Lancet, 395(10223), 483. Retrieved from https://www.ncbi.nlm.nih.gov/pmc/articles/PMC7133753/pdf/main.pdf

Meier, K., Glatz, T., Guijt, M. C., Piccininni, M., van der Meulen, M., Atmar, K., . . Najafabadi, A. H. Z. (2020). Public perspectives on social distancing and other protective measures in Europe: a cross-sectional survey study during the COVID-19 pandemic. medRxiv.

Merkley, E., Bridgman, A., Loewen, P. J., Owen, T., Ruths, D., \& Zhilin, O. (2020). A Rare Moment of Cross-Partisan Consensus: Elite and Public Response to the COVID-19 Pandemic in Canada. Canadian Journal of Political Science/Revue canadienne de science politique, 1-12. 
Social Distancing, Lockdown Obligatory, and Response Satisfaction During COVID-19 Pandemic:

Nazli, T., Raheem, A., \& Kishore, J. (2020). Perceptions and Practices of the Adult Population in Response to SARS-CoV-2 Pandemic in India. Epidemiology International (E-ISSN: 2455-7048), 5(2), 10-16.

NCDC. (2020). An update of COVID-19 outbreak in Nigeria Abuja, Nigeria2020 [cited 2020 04/05]. Available from: http:// covid19.ncdc.gov.ng/index.html.

Pakpour, A., \& Griffiths, M. (2020). The fear of CoVId-19 and its role in preventive behaviors. Journal of Concurrent Disorders.

Paterlini, M. (2020). On the front lines of coronavirus: the Italian response to covid-19. Bmj, 368.

Qazi, A., Qazi, J., Naseer, K., Zeeshan, M., Hardaker, G., Maitama, J. Z., \& Haruna, K. (2020). Analyzing Situational Awareness through Public Opinion to Predict Adoption of Social Distancing Amid Pandemic COVID-19. Journal of Medical Virology.

Shehu, H., \& Rao, P. D. (2020). Sociology of Covid-19: People Perceptions Regarding the Outbreak of the Pandemic among People of Northern, Nigeria. Sustainable Humanosphere, 16(1), 2078-2089.

University, J. H. (2020). An update of COVID-19 Map showing global outbreak 2020 [cited 2020 04/05]. Available on https://coronavirus.jhu.edu/map.html.

Van Bavel, J. J., Boggio, P., Capraro, V., Cichocka, A., Cikara, M., Crockett, M., . . Drury, J. (2020). Using social and behavioural science to support COVID-19 pandemic response.

Vijayaraghavan, P., \& SINGHAL, D. (2020). A Descriptive Study of Indian General Public's Psychological responses during COVID-19 Pandemic Lockdown Period in India.

Wang, C., Pan, R., Wan, X., Tan, Y., Xu, L., Ho, C. S., \& Ho, R. C. (2020). Immediate psychological responses and associated factors during the initial stage of the 2019 coronavirus disease (COVID-19) epidemic among the general population in China. International journal of environmental research and public health, 17(5), 1729.

Williams, S. N., Armitage, C. J., Tampe, T., \& Dienes, K. (2020). Public perceptions and experiences of social distancing and social isolation during the COVID-19 pandemic: A UK-based focus group study. medRxiv.

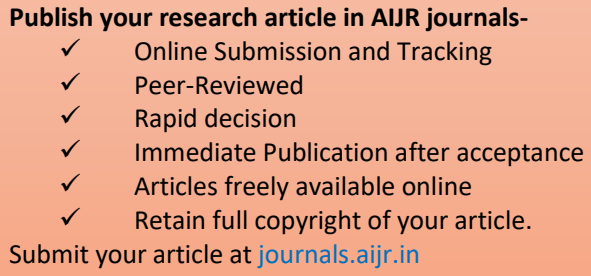

Publish your books with AIJR publisher-

$\checkmark \quad$ Publish with ISBN and DOI.

$\checkmark \quad$ Publish Thesis/Dissertation as Monograph.

$\checkmark \quad$ Publish Book Monograph.

$\checkmark \quad$ Publish Edited Volume/ Book.

$\checkmark \quad$ Publish Conference Proceedings

$\checkmark \quad$ Retain full copyright of your books.

Submit your manuscript at books.aijr.org 